\title{
Vorwort
}

\section{Maximilian Herberger"}

Einerseits braucht dieser Band kein Vorwort. Denn der Stimmungsbericht von Marion Goller - ein für die Berichterstattung über Tagungen eher unübliches und deswegen um so mehr zu begrüßendes Format - zeichnet die Dynamik der Debatten lebhaft und anschaulich nach. Wer nicht gezielt nach einem bestimmten Beitrag sucht, sollte die Lektüre mit diesem Stimmungsbericht beginnen.

Andererseits muss es doch ein Vorwort geben, denn so verlangen es die Gebräuche in der juristischen Community: Kein Tagungsband ohne Vorwort. Damit sind wir schon bei einem Kernthema der Frankfurter Zusammenkunft angekommen: Den in der Rechtswissenschaft hierzulande rituell gepflegten Verhaltensweisen und den diese begleitenden Befindlichkeiten. Was als üblich und angemessen empfunden wird, bestimmt sich danach. Es dürfte keine gewagte Hypothese sein, dass die etablierte akademische Rechtswissenschaft in ihrer großen Mehrheit dem Open-Access-Gedanken immer noch eher skeptisch gegenübersteht. Allerdings hat sich das Diskussionsklima in den letzten Jahren verändert. Grundsätzliche Ablehnung wird weniger öffentlich als im privaten Gespräch geäußert. Eine hart fundamentalskeptische Opposition war in Frankfurt nicht vertreten. Das förderte den entspannten und überwiegend friedlichen Gedankenaustausch in einer sehr angenehmen Atmosphäre. Man sollte jedoch - gerade dadurch inspiriert - vielleicht dem Gedanken nähertreten, bei anderer Gelegenheit die offene Konfrontation um Open Access in der Rechtswissenschaft einmal öffentlichkeitswirksam auszutragen. Zur Vorbereitung für ein solches Zusammentreffen sollten die Protagonisten der Anti-Open-Access-Szene aber den vorliegenden Band gründlich studieren. Er birgt nämlich eine Fülle von Überraschungen.

Die erste Überraschung für viele Diskutanten außerhalb des Kreises der Open-Access-Spezialisten dürfte die sein, dass „Open Access“ nicht schlicht mit der Vorstellung „Ich gebe einen Text einfach so zur weiteren beliebigen Verwendung frei“ $\mathrm{zu}$ identifizieren ist. Vielmehr stehen etwa in Gestalt der Creative Commons-Lizenzen differenzierte Lizenztypen bereit, die eine modifizierte Feinsteuerung erlauben. Zu dieser Thematik kann die Lektüre des Tagungsbandes manche Erkenntnis zu Tage fördern.

Ein weiteres Verdienst der Frankfurter Zusammenkunft besteht darin, dass die empirische Basis für das Räsonieren über Open Access in der Rechtswissenschaft durch sie erheblich verbreitert wurde. Dieser Fortschritt kann nicht hoch genug eingeschätzt werden, speisen sich doch manche rechtswissenschaftlichen Kontroversen über die causa „Open Access“ aus einer normativ grundierten anscheinend

* Prof. Dr. Maximilian Herberger ist Inhaber des Lehrstuhls für Bürgerliches Recht, Rechtstheorie und Rechtsinformatik an der Universität des Saarlandes, Direktor des dortigen Instituts für Rechtsinformatik und Leiter des Juristischen Internet-Projekts Saarbrücken. 
unerschütterlichen Selbstgewissheit. Diese ist dadurch gekennzeichnet, dass man aus dem Wissen um das Sollen die Überzeugung herleitet, man wisse zugleich, wie es ist. Diese Grundversuchung einer sich ausschließlich normativ verstehenden Rechtswissenschaft dürfte nicht nur beim Open-Access-Thema einem nötigen Erkenntnisfortschritt im Wege stehen.

Im Gespräch mit juristischen Autorinnen und Autoren trifft man in Deutschland oft auf die Ansicht, man müsse den Verlagen als gewissermaßen natürlichen Partnern in der Abwehr von für sie schädlichen Open-Access-Bestrebungen zur Seite stehen. Diese Einschätzungslage übersieht, dass zahlreiche Verlage bereits für sie nützliche Open-Access-Geschäftsmodelle entwickelt haben. Dazu wurden bei der Frankfurter Tagung interessante Einsichten vermittelt, deren Rezeption die Debatte - wiederum in empirischer Hinsicht - voranbringen kann. Es deutet sich an dieser Stelle übrigens auch an, dass der juristische Mainstream nach Art eines großen Tankers auf die lebendigen Weiterentwicklungen in der Open-Access-Landschaft eher zeitversetzt reagiert, manchmal wohl zu langsam.

Viel Raum nahmen in Frankfurt Überlegungen zu der Frage ein, warum - wovon wohl alle überzeugt waren - in der deutschen Rechtswissenschaft ein sektoral gepflegtes Gesprächsklima zum Thema „Open Access“ herrscht, das sich vom Diskurs in anderen Fächern wie beispielsweise den naturwissenschaftlich geprägten deutlich unterscheidet. Dazu wurden gehaltvolle Hypothesen entwickelt, die in den weiteren Erörterungen Beachtung finden sollten. Lässt man sich auf diese Gedankengänge ein, entdeckt man sehr schnell, dass es um mehr geht als um das Verhältnis zu Open-Access-Bestrebungen. Open-Access ist nur der Katalysator, der das Selbstverständnis der Rechtswissenschaft in ihrer kommunikativen Dimension auf die Probe stellt. Öffnet man den Blick in diese Richtung, muss die Rechtswissenschaft ihre Haltung fundamentaler durchdenken, als es eine Auseinandersetzung um „Open Access“ zunächst nahelegt.

Last but not least: Wo Juristinnen und Juristen zusammenkommen, ist die Erörterung von Rechtsfragen unausweichlich. Dies führte schnell zu der Frage: Wie viel Pflicht verträgt ein Open-Access-System, ohne dass legitime und schützenswerte Freiheitsspielräume eingeschränkt werden? Man kann den Tagungsband auch so lesen, dass diese Thematik stets im Hintergrund mitgedacht wird. An dieser Stelle wird dann zugleich eine spezifische Eigenart der Rechtswissenschaft deutlich, die sie definitiv von anderen Wissenschaften unterscheidet. In der Rechtswissenschaft sind nicht nur von Open-Access-Konzepten betroffene Publikationsakteure unterwegs. Vielmehr werden dort Gedanken vorbereitet, die dann im Rechtswesen verbindliche Geltung erlangen können und in den Publikationsbetrieb zurückwirken. Diese selbst-referentielle Komponente ist es, die eine Sonderstellung der Rechtswissenschaft begründet - aber auch eine besondere Verantwortung. 